\title{
GAMBARAN SIKAP DAN TINDAKAN IBU HAMIL DALAM MEMENUHI KEBUTUHAN NUTRISI SELAMA KEHAMILAN DI PUSKESMAS LANGSAT PEKANBARU
}

\author{
Yeni Yarnita, Maswarni, Intan Handiyani \\ Staff pengajar Jurusan D III Keperawatan Fakultas MIPA dan Kesehatan Universitas Muhammadiyah Riau \\ Email: Maswarni82@yahoo.co.id \\ Yarnitayeni@yahoo.co.id \\ Alumnus Jurusan D III Keperawatan-FMIPA. UMRI
}

\begin{abstract}
ABSTRAK
Nutrisi selama kehamilan adalah memelihara kebutuhan energi ibu, penyedia zat bagi pertumbuhan janin dan memberikan energi bagi proses laktasi atau menyusui, sehingga janin maupun bayi mendapatkan konsumsi zat gizi dari ibunya. Tujuan Penelitian ini adalah untuk mengetahui gambaran sikap dan tindakan ibu hamil dalam memenuhi nutrisi selama kehamilan di Puskesmas Langsat Pekanbaru. Metode penelitian yang digunakan adalah metode deskriptif dengan tehnik Accidental Sampling yaitu pengambilan sampel dilakukan dengan mengambil kasus atau responden yang kebetulan ada atau tersedia. Teknik pengumpulan data menggunakan kuesioner dan analisa data digunakan adalah univariate. Hasil penelitian menunjukan bahwa gambaran sikap dan tindakan ibu hamil dalam memenuhi kebutuhan nutrisi selama kehamilan di Puskesmas Langsat Pekanbaru dikategorikan kurang baik yaitu negative sebanyak 19 responden $(63,33 \%)$ dan tindakan kurang sebanyak 18 responden (60\%). Berdasarkan hasil penelitian tersebut disarankan agar upaya ibu hamil lebih baik dalam perawatan kehamilan dan kebutuhan nutrisi selama kehamilan.
\end{abstract}

Kata Kunci: Sikap dan Tindakan, Ibu Hamil, Nutrisi

\section{PENDAhuluan}

Ibu hamil memiliki kebutuhan makanan yang berbeda dengan ibu yang tidak hamil, karena ada janin yang tumbuh dirahimnya. Kebutuhan makanan dilihat bukan hanya dalam porsi tetapi harus ditentukan pada mutu zat-zat gizi yang terkandung dalam makanan yang dikonsumsi (anonym,2008). Untuk pertumbuhan maupun aktivitas janin memerlukan makanan yang disalurkan melalui plasenta. Untuk itu ibu hamil harus mendapat gizi yang cukup untuk dirinya sendiri maupun bagi janinnya. Maka bagi ibu hamil, kualitas maupun jumlah makanan yang biasanya cukup untuk kesehatannya harus ditambah dengan zat-zat gizi dan energi agar pertumbuhan janin berjalan dengan baik. Selama hamil ibu akan mengalami banyak perubahan dalam tubuhnya agar siap membesarkan janin yang dikandungnya, memudahkan kelahiran, dan untuk memproduksi ASI bagi bayi yang akan dilahirkannya (Francin, 2005).

Bila ibu mengalami kekurangan nutrisi selama hamil akan menimbulkan masalah, baik pada ibu maupun janin yang dikandungnya, antara lain: anemia, perdarahan dan berat badan ibu tidak bertambah secara normal, kurang gizi juga dapat mempengaruhi proses persalinan dimana dapat mengakibatkan persalinan sulit dan lama.

WHO melaporkan bahwa setengah ibu hamil mengalami anemia, secara global 55\% dimana secara bermakna trimester III lebih tinggi mengalami anemia dibandingkan dengan trimester I dan II. Masalah ini disebabkan kurangnya defesiensi zat besi dengan defisiensi zat gizi lainnya trimester III sangat membutuhkan nutrisi karena janinnya sedang berkembang. (Mc Carthy dan Maine, 1992).

Di Indonesia prevalensi anemia tahun 1970an, wanita hamil sekitar 46,5-70\% pada Survey Kesehatan Rumah Tangga (SKRT) tahun 1992 dengan angka anemia ibu hamil sebesar $63,5 \%$ sedangkan data SKRT turun menjadi 50,9\%. Pada tahun 1999 didapatkan anemia gizi pada ibu hamil sebesar 39,5\%, tahun 2001, didapatkan anemia zat gizi pada ibu hamil mencapai $40,1 \%$, banyak fktor yang terkait dengan status anemia 
ibu hamil yaitu status sosial ekonomi, serta perolehan tablet zat besi (Fe) (Pasaribu, 2006).

Berdasarkan survei awal yang peneliti laksanakan tanggal 04 November 2008 terhadap ibu hamil di Puskesmas Langsat Pekanbaru didapatkn hasil 6 Orang $(60 \%)$ ibu hamil kurang pengetahuan tentanng nutrisi ibu hamil, dan hanya 4 Orang (40\%) ibu hamil yang paham tentang nutrisi ibu hamil. Maka dari itu peneliti ingin lebih mengetahui bagai mana gambaran sikap dan tindakan ibu hamil dalm memenuhi kebutuhan nutrisi selama kehamilan di Puskesmas Langsat Pekanbaru. Oleh karena itu peneliti tertarik untuk melakukan penelitian dan mengambil judul: "gambaran sikap dan tindakan ibu hamil dalm memenuhi kebutuhan nutrisi selama kehamilan di puskesmas langsat pekanbaru".

\section{METODOLOGI PENELITIAN}

Jenis penelitian yang digunakan dalam penelitian ini adalah deskriptif, yaitu suatu desain penelitian yang dilakukan dengan tujuan utama untuk menggambarkan suatu objek penelitian (Notoatmodjo, 2005). Dimana dalam penelitian ini hanya menggambarkan sikap dan tindakan ibu hamil dalam memenuhi kebutuhan nutrisi selama kehamilan di puskesmas langsat pekanbaru. Populasi dalam penelitian ini adalah seluruh klien yang berada puskesmas langsat pekanbaru dengan jumlah sampel 30 responden. Dalam analisa data menggunakan analisa secara manual (univariate). Pengukuran sikap dengan menggunakan skala likert dengan mengggunakan ketegori

a. Pernyataan Positif
1) Sangat setuju
2) Setuju
$=(4)$
3) Tidak setuju
$=(3)$
4) Sangat tidak setuju
$=(2)$
$=(1)$

Dengan tingkatan sikap:

1) Sikap Positif $>60 \%$

2) Sikap Negatif $<60 \%$

b. Pernyataan Negatif
1) Sangat setuju
2) Setuju
3) Tidak setuju
$=(2)$
4) Sangat tidak setuju
$=(3)$
$=(4)$

(Ridwan, 2003)

Sedangkan tindakan menggunakan rumus menurut Arikunto (2002),

$$
\text { Rumus: } \quad P=\frac{F}{N} \times 100 \%
$$

Dengan hasil perhitungan persentase dimasukkan dalam kriteria standard objektif menurut Nursalam (2003), sebagai berikut:

$\begin{array}{ll}\text { Baik } & : 76-100 \% \\ \text { Cukup } & : 56-75 \% \\ \text { Kurang } & :<56 \%\end{array}$

\section{HASIL DAN PEMBAHASAN}

Berdasarkan hasil penelitian yang di lakukan pada tanggal 7 - 9 Juli 2008 di Puskesmas Langsat Pekanbaru, yang berjudul "Gambaran Sikap dan Tindakan Ibu Hamil Dalam Memenuhi Kebutuhan Nutrisi Selama Kehamilan di Puskesmas Langsat Pekanbaru", sebagai berikut: Sikap negatif sebanyak 21 responden $(70 \%$ responden). Peneliti menduga bahwa sikap responden yang mayoritas negatif terhadap memenuhi kebutuhan nutrisi selama kehamilan dapat dipengaruhi oleh beberapa faktor yaitu informasi, sumber informasi dan tingkat pendidikan.

Sedangkan untuk tindakan ibu hamil dalam memenuhi kebutuhan nutrisi selama kehamilan di Puskesmas Langsat Pekanbaru tahun 2008 mayoritas dalam kategori kurang sebanyak 21 responden $(56,67 \%)$. Hal ini di akibatkan oleh beberapa faktor di antaranya pendidikan dan informsai.

\section{DAFTAR PUSTAKA}

Arikunto, S. (2002). Prosedur Penelitian Suatu Pendekatan Praktek. Jakarta: Rineka Cipta

Ardianti.(2004). Gambaran Sikap\& Tindakan Ibu Hamil dalam Perawatan Kehamilan dan Kebutuhan Gizi pada Ibu Hamil. http://situs.kesrepro.info, diperoleh pada tanggal 2 Agustus 2010

Anonim. 2008. Asupan Gizi Selama Kehamilan. Diperoleh tanggal 11 Juny 2009 dari http://addy1571.files.wordpress.com.

Astri. (2004). Gambaran sikap dan tindakan ibu hamil dalam pemenuhan nutrisi. Jawa Barat: Alfebeta 
Azwar. (2003), Hubungan Prilaku dengan informasi, http//www.google.com, Diperoleh pada tanggal 20 Oktober 2009

Behrman.E.E dkk. (1999). Dalam Buku Hidayat. A.A, 2005 Pengantar Ilmu Keperawatan. Edisi Pertama - Jakarta Salemba Medika.

Bobak,RN dkk. (2005). Keperawatan Maternitas. Jakarta: EGC

Brock Katie dkk.(2005). Nutrisi, Medikasi Dan Senam Kehamilan. PrestasinPustakarya Jakarta

Chureh. (1998). Media Masa Sebagai Sumber Informasi. www.google.com.

Diperoleh pada tanggal Juli 2010

Gustina (2002), Kesadaran Individu Terhadap Pendidikan, dari www.google.com diperoleh pada tanggal 25 Juli 2010

Hasan, I. (2004), Analisa Data Penelitian, Jakarta Bumi Aksara

Hidayat, A. 2003. Riset Keperawatan dan Teknik Penulisan Ilmiah. Jakarta: EGC.

Hidayat. Azis Alimul (2005), Pengantar Ilmu Keperawatan. Edisi Pertama, Jakarta, Salemba Medika

Huliana. 2001. Panduan Menjalani Kehamilan Sehat. Puspa Swara. Jakarta

--------. (2008). Kebutuhan Nutrisi Pada Ibu Hamil, diperoleh pada tanggal 20 July 2009. dari http://.www nursingailiyun.blogspot.com

--------. (2009). Konsep Nutrisi, Diperoleh tanggal 24 july 2009. dari http://hidayat.wordpresess.com

Mansjoer, A. (2004). Kapita Selekta Kedokteran Edisi Ketiga Jilid Pertama. Jakarta: Media Aesculapius Fakultas Kedokteran Universitas Indonesia

$$
\text { (2001). Kapita Selekta }
$$

Kedokteran. Jakarta: Media Aesculapius
Muliarini. Prita. (2010), Pola Makan Dan Gaya Hidup Sehat Selama Kehamilan Edisi Pertama Yogyakarta: Muha Medika

Murtiwi.(2009), Persepsi dan Sikap serta Tindakan ibu hamil dalam memenuhi kebutuhan nutrisi selama kehamilan. www.google.com. Diperoleh pada tanggal Juli 2010

Notoadmodjo S, 2003, Pendidikan dan Perilaku Kesehatan, Rineka Cipta: Jakarta

Notoatmodjo, S. 2002. Metodologi Penelitian Kesehatan. Jakarta: Rineka Cipta.

Permata, (2002), Hubungan Informasi Dengan Pengetahuan. www,google.com. diperoleh pada tanggal 13 juli 2010

Pudjiadi, S. (2003). Ilmu Gizi Klinis. Jakarta: Gaya Baru

Pudjiadi. (2001). Dalam Buku Hidayat. A.A 2005. Pengantar Ilmu Perawatan Edisi Pertama Jakarta: Salemba Medika

Ratna Ardianti. (2004). Pemenuhan Nutrisi Pada Ibu Hamil. www.google.com.

Diperoleh pada tanggal 26 Juli 2010

Ridwan. (2003), Skala Pengukuran, Variable Penelitian, Jawab Barat, Alpabeta

Rusli. (2001). Hubungan Informasi dengan ibu hamil. Jakarta: Balai Aksara

Sayogo. Safitri. (2007). Nutrisi Pada Ibu Hamil. Jakarta 2007

Sulistijani.(2001). Menjaga Kesehatan Bayi. Jakarta:Puspawara

Suroso, (2003), Pemenuhan Nutrisi, Info.@nutrisi.com diambil pada tanggal 3 Juli 2010

Yozardi, Dini. (2006). Gizi Ibu Hamil. Jakarta, Batavia Press 